\title{
In for a Penny, in for a Pound: Methylphenidate Reduces the Inhibitory Effect of High Stakes on Persistent Risky Choice
}

\author{
Daniel Campbell-Meiklejohn, ${ }^{1,2}$ Arndis Simonsen, ${ }^{1}$ Jørgen Scheel-Krüger, ${ }^{1}$ Victoria Wohlert, ${ }^{1}$ Trine Gjerløff, ${ }^{1}$ \\ Chris D. Frith, ${ }^{1,3,4}$ Robert D. Rogers, ${ }^{5}$ Andreas Roepstorff, ${ }^{1,6}$ and Arne Møller ${ }^{1}$ \\ ${ }^{1}$ Centre of Functionally Integrative Neuroscience, Aarhus University, 8000 Aarhus, Denmark, ${ }^{2}$ Center for Neural Science, New York University, New York \\ 10003, ${ }^{3}$ Wellcome Trust Centre for Neuroimaging, University College London, London WC1N 3BG, United Kingdom, ${ }^{4}$ All Souls College, University of \\ Oxford, Oxford OX1 4AL, United Kingdom, ${ }^{5}$ Department of Psychiatry, University of Oxford, Warneford Hospital, Oxford OX3 7JX, United Kingdom, and \\ ${ }^{6}$ Interacting Minds Centre, Aarhus University, 8000, Aarhus C, Denmark
}

Methylphenidate (MPH) is a stimulant that increases extracellular levels of dopamine and noradrenaline. It can diminish risky decisionmaking tendencies in certain clinical populations. MPH is also used, without license, by healthy adults, but the impact on their decisionmaking is not well established. Previous work has found that dopamine receptor activity of healthy adults can modulate the influence of stake magnitude on decisions to persistently gamble after incurring a loss. In this study, we tested for modulation of this effect by MPH in 40 healthy human adults. In a double-blind experiment, 20 subjects received $20 \mathrm{mg}$ of MPH, while 20 matched controls received a placebo. All were provided with 30 rounds of opportunities to accept an incurred loss from their assets or opt for a "double-or-nothing" gamble that would either avoid or double it. Rounds began with a variable loss that would double with every failed gamble until it was accepted, recovered, or reached a specified maximum. Probability of recovery on any gamble was low and ambiguous. Subjects receiving placebo gambled less as the magnitude of the stake was raised and as the magnitude of accumulated loss escalated over the course of the task. In contrast, subjects treated with MPH gambled at a consistent rate, well above chance, across all stakes and trials. Trait reward responsiveness also reduced the impact of high stakes. The findings suggest that elevated catecholamine activity by MPH can disrupt inhibitory influences on persistent risky choice in healthy adults.

\section{Introduction}

How does one know when to quit? Persisting with uncertainty can make up for lost investment, but it can also make matters worse. With this paper, we examine the effect of the psychostimulant methylphenidate (MPH; Ritalin) on the influence of cues to inhibit persistent risky choice.

MPH increases extracellular levels of dopamine and noradrenaline (Volkow et al., 2001; Berridge et al., 2006; Gamo et al., 2010). It is also an established treatment of attention deficit hyperactivity disorder (Wilens, 2008). In various clinical contexts, MPH can bring certain risky decision-making tendencies closer to those of untreated healthy individuals (Rahman et al., 2006; DeVito et al., 2008; Shiels et al., 2009). However, MPH is also increasingly used as a so-called "smart pill" by healthy adults (Smith and Farah, 2011), for which its effects on risky decision making are not well established. The beneficial effects of MPH

Received Jan. 11, 2012; revised July 23, 2012; accepted July 26, 2012.

Author contributions: D.C.-M., J.S.-K., C.D.F., A.R., and A.M. designed research; A.S., V.W., T.G., and A.M. performed research; D.C.-M. contributed unpublished reagents/analytic tools; D.C.-M. analyzed data; D.C.-M., C.D.F., and R.D.R. wrote the paper.

This work was funded by a Danish Council for Strategic Research and the Danish Council for Independent Research Problem Gambling grant awarded to D.C.-M., a Danish National Research Foundation Niels Bohr Visiting Professorship to C.D.F., and the Danish Medical Research Council. We thank Dr. Bradley Doll for statistical analysis advice.

Correspondence should be addressed to Dr. Daniel Campbell-Meiklejohn, Center for Neural Science, New York University, 4 Washington Place, Room 809, New York, NY 10003. E-mail: dan.cfin@gmail.com.

DOI:10.1523/JNEUROSCI.0151-12.2012

Copyright $\odot 2012$ the authors $\quad 0270-6474 / 12 / 3213032-07 \$ 15.00 / 0$ likely depend on baseline catecholamine activity and optimal neuromodulation for a particular cognition (Cools et al., 2001; Clatworthy et al., 2009; Robbins and Arnsten, 2009). Despite normalizing clinical effects, MPH could detrimentally affect risky decision making of individuals without catecholamine deficits.

There is good evidence to suggest this would be the case. First, $\mathrm{MPH}$ can increase affective and neural responses to reward in healthy adults (Volkow et al., 2002, 2004), which is presumably indicative of enhanced estimates of reward utility. Second, MPH may alter estimates of probability. Among its pharmacological effects, $\mathrm{MPH}$ indirectly increases $\mathrm{D}_{2}$ and $\mathrm{D}_{3}$ receptor binding in the healthy human striatum (Volkow et al., 2001; Clatworthy et al., 2009). In Parkinson's patients, direct activation of $\mathrm{D}_{2} / \mathrm{D}_{3}$ receptors by agonists can inhibit learning about low outcome probability due, theoretically, to masked expression of midbrain dopamine fluctuations (Frank et al., 2004; Cools et al., 2006). $\mathrm{D}_{2} / \mathrm{D}_{3}$ agonists are also associated with pathological gambling onset, which inherently involves an increase of risky decision making when it is seemingly unwise to do so (Weintraub et al., 2010). In healthy adults, direct $D_{2} / D_{3}$ activation alters the inhibiting influence of stake size on decisions to take double-or-nothing risks after experiencing loss (CampbellMeiklejohn et al., 2011).

Double-or-nothing gambles set the magnitude of potential gain and the magnitude of potential loss to the magnitude of the cumulative prior loss. These are risky opportunities for complete loss recovery.

High stakes can reduce tendencies to accept risks (Binswanger, 1981; Holt and Laury, 2002, 2005). This effect, however, may be 
offset by increased reward incentive or by overestimation of reward probability. As discussed above, both are potential effects of $\mathrm{MPH}$. We tested whether $\mathrm{MPH}$, like direct $\mathrm{D}_{2} / \mathrm{D}_{3}$ receptor agonists, would diminish the effect of high stakes to take double-ornothing risks in healthy adults. To investigate the potential role of higher affective responses to reward, we tested whether high trait reward responsiveness would have a similar effect.

\section{Materials and Methods}

The ethics committee of Central Jutland Region, Denmark, approved the study, and all subjects gave written informed consent.

\section{Screening}

Subjects were given a physical examination by a physician and screened with the Structured Clinical Interview for Diagnostic and Statistical Manual of Mental Disorders, 4th edition (DSM-IV) Axis I disorders to ensure that none of the following exclusion criteria were met: (1) major physical illness, head trauma or pregnancy; (2) use of psychotropic medication in the previous 3 months; (3) current or previous DSM-IV anxiety or mood disorder; (4) current or previous DSM-IV psychotic disorder; and (5) current or previous DSM-IV substance use disorder. Subjects were screened for pathological gambling with the South Oaks Gambling Screen (Lesieur and Blume, 1987). There was no evidence of a problem or pathological gambling. Use of hormonal contraception was not an exclusion criterion.

\section{Trait measures}

After screening, we recorded trait measures of anxiety [Spielberger StateTrait Anxiety Index (STAI)] (Spielberger, 1970), gambling-related cognition (Gambling Related Cognition Scale) (Raylu and Oei, 2004), self-reported chasing tendency (O'Connor and Dickerson, 2003), Behavioral Inhibition System-Behavioral Activation System Scales (BIS-BAS) (Carver and White, 1994), intelligence quotient (IQ) (Wechsler, 2005), and mood [Positive and Negative Affect Scale (PANAS)] (Watson et al., 1988). The BIS-BAS contained the following four subscales: behavioral inhibition (BIS), reward responsiveness (BAS-R), drive (BAS-D), and fun-seeking (BAS-F).

\section{Group assignment}

Forty healthy adults (all female) were accepted to the study. From these volunteers, 20 pairs were formed, matched on age (mean 23 years, SD 2.8 years) years of education (mean 13.8, SD 1.8), performance IQ [Wechsler Adult Intelligence Scale III (WAIS-III Matrix Reasoning, scaled; mean 12.8, SD 1.8), and verbal IQ (WAIS-III Vocabulary, scaled; mean 11.5, $\mathrm{SD}$ 1.9). One subject of each pair was randomly allocated to a drug group, $\mathrm{MPH}$ or placebo, with a double-blind procedure.

\section{State measures}

On arrival at the laboratory, subjects completed baseline assessments of state anxiety (STAI) and mood (PANAS). These were assessed again at estimated peak MPH absorption and immediately before cognitive testing. Changes from before to after drug absorption were calculated for each measure. Side effects of nausea and headache were assessed just before testing as a self-reported rating from 0 (not at all) to 7 (severe).

\section{Drug administration}

All subjects were tested within the first $12 \mathrm{~d}$ of their menstrual cycle and were asked to refrain from caffeine for $24 \mathrm{~h}$ before the study. Subjects received either MPH $(2 \times 10 \mathrm{mg})$ or placebo at 11:00 A.M. on test day, $1.5 \mathrm{~h}$ before behavioral testing.

\section{The loss-chasing task}

Named for the decision to "chase" losses (gambling to recover them) (Lesieur, 1984; O'Connor and Dickerson, 2003), variations of this task have been described previously (Campbell-Meiklejohn et al., 2008, 2011; Rogers et al., 2011). In this experiment, we implemented a fixed probability of winning on any trial, randomized the initial stake presented, and limited the task to 30 rounds. Feedback was translated to Danish, and Danish currency was used.

Reward structure. At the start of the game, subjects were told that they had a fictional 192,000 Danish kroner (kr) (U.S. \$35,000) in total assets and that the subject who loses the least fictional money during the game would receive a real prize of $500 \mathrm{kr}$ (U.S. \$88). Subjects were not told how others had performed, so all they could do was try to achieve the best score that they could. Mixtures of nominal and actual rewards such as this have been used in behavioral economics to produce behavior qualitatively and quantitatively similar to that observed outside the laboratory (Cubitt et al., 1998). Positive outcomes with this payoff structure significantly activate brain regions associated with primary and financial rewards (Campbell-Meiklejohn et al., 2008).

Rounds and trials. The game (Fig. 1) consisted of 30 "rounds." Each round consisted of one to six "trials." Each trial followed a loss. The first trial of a round began with an imposed loss of $100,200,400,800$, or 1600 $\mathrm{kr}$, chosen at random. The round loss appeared below two choices: "Quit" and "Play." This value was also the amount that could be gained or lost by choosing Play (i.e., chasing the loss). We call this amount the "stake." If the gamble's outcome was positive, the stake was won, prior round losses were recovered, and the round ended. If the outcome was negative, the stake was lost and added to prior round losses (i.e., the round loss doubled), and subjects were given another double-or-nothing opportunity to fully recover round losses on the next trial of the round. This continued until a maximum round loss of $6400 \mathrm{kr}$ was reached. If this maximum was reached, the round ended and $6400 \mathrm{kr}$ was subtracted from the subject's total assets. Choosing Quit subtracted the round losses up to that point from the subject's assets and ended the round immediately. Due to the random starting stake of rounds, the number of losses preceding a trial in a round (one to six) and the analyzed stake sizes (see Statistical Analysis) shared only 9\% of their variance.

Probability of winning. A total of $15 \%$ of Play choices would result in a reward. The probability of winning on one trial was independent of the probability of winning on others. This means that the probability of recovering losses of a round would range from 30 to $90 \%$ (with two to six trials), if every choice were to play, depending on the starting stake of a round. Subjects, however, were not told these probabilities. Decisions were made with ambiguous uncertainty.

Dependent variables. The main dependent measure of interest was the decision to gamble $(1=$ Play, $0=$ Quit $)$. The number and proportion of decisions to switch choices from the previous trial were also measured. For comparison to a previous study (Campbell-Meiklejohn et al., 2011), we also measured overall play ratios (choices to play/all choices), chase value ratios (mean stake of choices to play/overall mean stake), quit value ratio (mean stake of choices to quit/overall mean stake), and deliberation time.

Independent variables. Within-subject predictors of interest were stake size and accumulated losses (from all rounds). Between-subject predictors were drug group $(\mathrm{MPH}+1$, placebo -1$)$, and independently, specific BIS/BAS personality measures.

Strategy. To encourage deliberation on each trial, subjects were informed (correctly) that they would not achieve the best possible score by exclusively playing or quitting. However, subjects were still free to use these strategies, and there was no penalty for doing so. No information was provided about overall accumulated game losses during the task.

\section{Statistical analysis}

Between-group comparisons were performed by independent sample $t$ test or appropriate non-parametric analysis (e.g., Welch's $t$ test for unequal variances), using SPSS 19 (IBM) (Field, 2009). Relationships of predictors to choices were assessed by multilevel mixed logistic regressions. Relationships of predictors to reaction times were assessed by multilevel mixed linear regression. The slope and intercept of the relationship between within-subject predictors and dependent measures were allowed to vary, as random effects, between subjects. Between-subject predictors were treated as fixed effects. Modeling of correlation parameters for random effects was determined using likelihood ratio testing. If no difference was observed, the more parsimonious (uncorrelated) model was used. All continuous variables were mean corrected. Regressions were performed in $\mathrm{R}$ ( $\mathrm{R}$ Development Core Team) using the lme4 linear mixed model package for $\mathrm{R}$ (Bates and Maechler, 2009). Parameter estimates, SE of estimate, test statistics ( $t$ or $z, p)$, and SD of random effects $\left(\mathrm{SD}_{\mathrm{RE}}\right)$ of regressions are reported in tables. Correlations between measures were tested with Pearson correlation coefficients. 


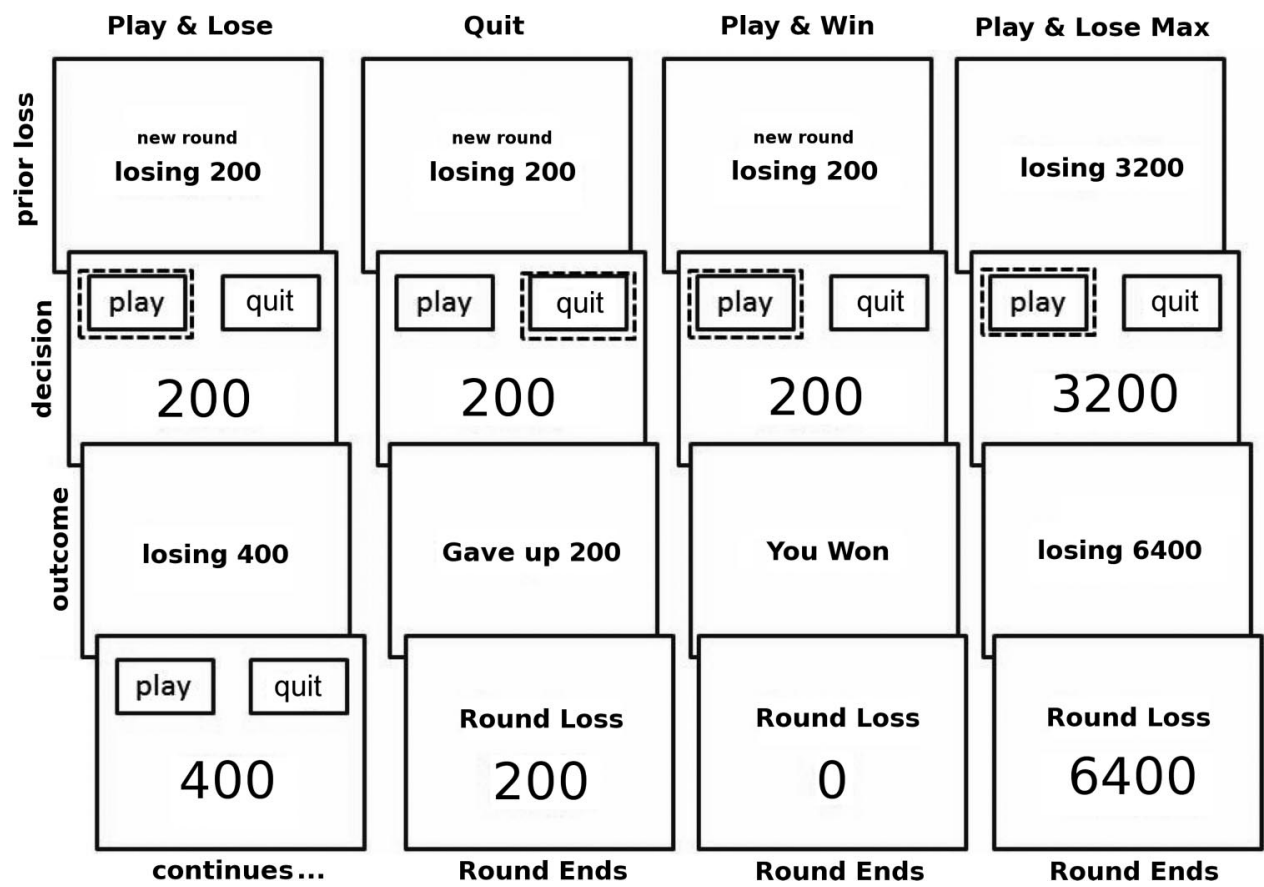

Figure 1. The options for each choice—Play or Quit—appeared randomly on the left and right side of the computer display during the decision phase. Each round began with a loss (also the stake) displayed for $3 \mathrm{~s}$. This was followed by a choice to accept that loss (Quit) and end the round or to risk the value of the loss (Play) to try and recover it. Subjects responded by pressing keys on a mouse corresponding to the side of their desired choice. Choices were randomly assigned to sides of the display from round to round. Outcome displays $(2 \mathrm{~s})$ indicated whether subjects had won a gamble and that no money was lost (Play \& Win); whether they had lost a gamble and the amount lost (Play \& Lose); or the amount lost from assets if subjects chose to give up (Quit). If the loss reached $6400 \mathrm{kr}$, the round automatically ended with no chance of recovery (Play \& Lose Max). At the end of each round, subjects were informed of the amount that would be taken off their final total as a result of that round. There was no time limit for making a decision. The dotted line indicates the subject's choice but was not displayed to subjects. Words were translated to Danish. Displays were presented to subjects in color with losses, negative outcomes, and Quit displays indicated in red font. Positive outcomes were indicated in green.

Demographic, trait, and state measures. To ensure that group effects on task behavior were not due to differences of demographic, trait, or state measures, these variables were compared between groups and tested for correlation to behavioral measures if differences were significant.

Task reinforcement. To ensure groups experienced similar stakes and reinforcement during the task, between-group comparisons were used to test for differences of mean (1) win frequency, (2) win magnitude, (3) losses in a round before a win, and (4) initial round loss.

Choice. Overall play ratio was compared, between groups and within each group, to chance (0.5). Number and proportion of decisions to switch from the previous choice were also compared between groups.

The effect of stake. For investigations of stake size influence, we only analyzed choices at stakes that were (1) presented with equal frequency in both drug groups ( $3200 \mathrm{kr}$ was not) and (2) presented frequently enough to generate meaningful play ratio statistics (100 kr was not). We used a multilevel mixed logistic regression that modeled the intercept and stake (in $100 \mathrm{kr}$ units) magnitude as uncorrelated random effects, and two fixed effects: drug group $(\mathrm{MPH}=+1$, placebo $=-1)$; and drug group $\times$ stake interaction. When a drug group $\times$ stake interaction was confirmed, we investigated further by a separate random-effects analysis of stake effects in each drug group. We then compared play ratios at each individual stake between groups. To test for the stake $\times$ group effect without the first trial of the round (limiting chasing to losses caused by the gambling), we repeated the main regression on this limited dataset.

The effect of accumulated loss. To estimate the effect of accumulated loss (all rounds) on the choice to Play or Quit, we performed a multilevel mixed logistic regression containing the intercept and accumulated loss (in $1000 \mathrm{kr}$ units) as uncorrelated random effects, and two fixed effects [drug group $(\mathrm{MPH}=+1$, placebo $=-1)$ and its interaction with accumulated loss]. When an interaction effect was confirmed, we investigated further by a separate random-effects analysis of accumulated loss effects in each drug group.

$B I S / B A S$. To investigate the role of affective responses to reward and other reward-related processes on stake effects, reward responsiveness
(BAS-R), fun-seeking (BAS-F), and drive (BAS-D) were each tested as between-subject predictors of the effect of stake on choice. Multilevel mixed logistic regression models included the intercept and stake as uncorrelated random effects, and two fixed effect parameters: the respective BIS/BAS subscore and its interaction with stake. An identical modeling procedure was used to investigate the effect of BIS/BAS trait interactions with accumulated loss on choice.

Deliberation time. Mean deliberation time was compared between groups and between decisions. We modeled the influence of stake on deliberation time with a multilevel mixed linear regression. The model included correlated random effects of intercept and stake, and fixed effects of drug group and its interaction with stake. Significance tests of fixed effect parameters were conducted as likelihood ratio tests between nested models, with and without the examined parameter. To test for an effect of accumulated losses on deliberation time, we performed an identical regression with accumulated loss, in the place of stake.

\section{Results}

\section{Demographic, trait, and state measures}

Two subjects (both MPH) from the group of 40 reported a severe headache (score $>5$ of 7 ) just before performing the task. We removed these subjects from subsequent analysis. We also removed one MPH subject with an outlier BAS-D score ( $>2$ SDs above the overall mean), which is known to predict positive affective responses to reward anticipation (Carver and White, 1994) and may have generated a false-positive result. In the remaining dataset, trait anxiety differed slightly between groups (placebo $29 \pm 5(\mathrm{SD}) ; \mathrm{MPH} 26 \pm 4 ; t_{(35)}=2.1, p<0.04$ ) but did not correlate with any behavioral measure ( $p$ values $>0.38$ ). Groups were equal on all other state and trait measures $(p$ values $>0.15$ ). 
Table 1. General persistence measures

\begin{tabular}{|c|c|c|c|c|}
\hline \multirow[b]{3}{*}{ Measure } & \multicolumn{4}{|l|}{ Drug group } \\
\hline & \multicolumn{2}{|l|}{ Placebo } & \multicolumn{2}{|l|}{ MPH } \\
\hline & Mean & SD & Mean & SD \\
\hline Plays: all choices & 0.69 & 0.14 & 0.73 & 0.12 \\
\hline Switches from previous: all choices & 0.44 & 0.16 & 0.40 & 0.14 \\
\hline Mean stake Play: mean overall stake & 0.87 & 0.22 & 1.03 & 0.15 \\
\hline Mean stake Quit: mean overall stake & 1.12 & 0.41 & 0.93 & 0.41 \\
\hline Deliberation time, Play (ms) & 1045 & 296 & 1329 & 549 \\
\hline Deliberation time, Quit (ms) & 1196 & 414 & 1434 & 500 \\
\hline Money lost (kr) & 47,031 & 16,988 & 58,843 & 17,239 \\
\hline
\end{tabular}

Table 2. Effects of stake and drug on choice

\begin{tabular}{lrrrrr}
\hline & $\beta$ & SE & $Z$ & $p>z$ & $S_{\mathrm{RE}}$ \\
\hline Stake $\times$ drug & & & & & \\
$\quad$ Intercept & 1.1315 & 0.1658 & 6.826 & 0.00 & 0.92 \\
$\quad$ Stake (100 kr units) & -0.4595 & 0.2609 & -1.761 & 0.08 & 1.41 \\
$\quad$ Drug: MPH (1)/placebo (-1) & 0.1387 & 0.1658 & 0.837 & 0.40 & \\
Drug $\times$ stake & 0.633 & 0.2609 & 2.426 & $0.015^{*}$ & \\
$\quad$ MPH & & & & & \\
$\quad$ Intercept) & 1.24 & 0.17 & 7.29 & $0.00^{*}$ & 0.59 \\
$\quad$ Stake & 0.16 & 0.38 & 0.43 & 0.66 & 1.40 \\
$\quad$ Placebo & & & & & \\
$\quad$ Intercept & 0.96 & 0.31 & 3.04 & $0.002^{*}$ & 1.34 \\
$\quad$ Stake & -1.14 & 0.44 & -2.59 & $0.009^{*}$ & 1.78 \\
\hline * $<<0.05$ & & & & &
\end{tabular}

Task reinforcement

The groups experienced equal mean (1) win frequency [MPH $7.3 \pm 0.89$ (SE); placebo $6.6 \pm 0.86 ; p>0.42]$, (2) win magnitude $(\mathrm{MPH} 1213 \pm 188$; placebo $1041 \pm 97 ; p>0.98)$, (3) losses in a round before win $(\mathrm{MPH} 1.91 \pm 0.11$; placebo: $2.1 \pm 0.08 ; p>$ 0.23 ), and (4) initial round loss (MPH $625 \pm 29$; placebo $635 \pm$ $25 ; p>0.65)$. BIS/BAS subscores did not correlate significantly with any of these measures ( $p$ values $>0.3$ ).

\section{Choice}

Both groups gambled significantly more than chance $\left(\mathrm{MPH}: t_{(16)}=\right.$ $8, p<0.001$; placebo: $\left.t_{(19)}=6.1, p<0.001\right)$, but overall gambling rates did not differ between groups or vary with BIS/BAS score ( $p$ values $>0.36$ ). Likewise, the overall tendency to switch behavior from the previous choice did not differ between groups ( $p$ values $>0.5$ ). See Table 1 .

\section{The effect of stake}

We observed a significant interaction between the effect of drug group and the effect of stake magnitude (see Table 2). This effect was due to the absence of stake-induced inhibition in the MPH group, which was otherwise present in the placebo group. If looking only at trials that followed a loss induced by the subject (i.e., removing the first trial of each round from analysis), the interaction between stake and drug remained significant $(\beta=0.69, z=1.99, p<0.05)$. Between-group comparisons showed that the MPH group gambled significantly more for $1600 \mathrm{kr}$ stakes (MPH $0.74 \pm 0.05$; placebo $\left.0.54 \pm 0.07 ; t_{(35)}=2.3, p<0.03\right)$ and, as a trend, gambled less for $200 \mathrm{kr}$ stakes (MPH: $0.71 \pm 0.06$; placebo $0.84 \pm 0.03 ; t_{(24)}$ $=1.8, p<0.08$ ) (Fig. 2). Corresponding to multilevel regression effects of stake, chase value ratio was higher in the MPH group $\left(t_{(35)}=2.41, p<0.022\right)$. Quit value ratios did not differ significantly between groups $(p>0.16)$. See Table 2 .

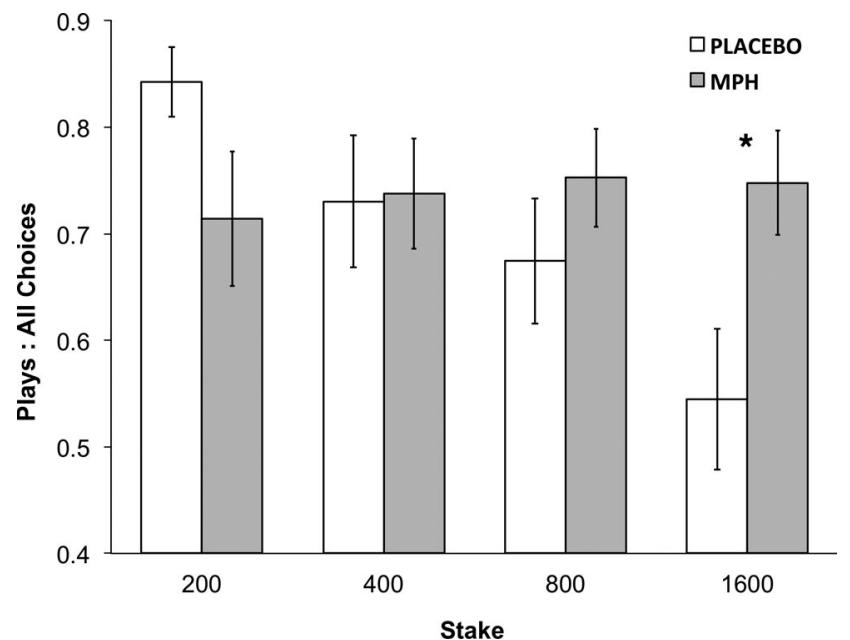

Figure 2. Interaction of drug and stake on risky persistence. Probability of decision to accept a double-or-nothing gamble across various magnitudes of stake. Gambling probability was reduced with increasing stakes in the placebo group but not the MPH group (see Table 2). This led to a significant difference of gambling probability at high stakes (1600 kr). Error bars are \pm 1 SE (between subjects). ${ }^{*} p<0.05$.

Table 3. Effects of game losses and drug on choice

\begin{tabular}{lrrrll}
\hline & $\beta$ & SE & $Z$ & $p>z$ & $S_{\text {RE }}$ \\
\hline Game losses $\times$ drug group & & & & & \\
$\quad$ Intercept & 0.96 & 0.12 & 7.8 & 0.00 & 0.75 \\
Game losses (1000 kr units) & -0.01 & 0.00 & -2.4 & $0.02^{*}$ & 0.00 \\
$\quad$ Drug: MPH (1)/placebo (-1) & 0.11 & 0.12 & 0.86 & 0.39 & \\
Game losses $\times$ drug & 0.01 & 0.00 & 2.18 & $0.03^{*}$ & \\
$\quad$ MPH & & & & & \\
$\quad$ Intercept & 1.08 & 0.15 & 7.01 & 0.00 & 0.55 \\
$\quad$ Game losses & 0.00 & 0.00 & 0.01 & 1.00 & 0.00 \\
Placebo & & & & & \\
$\quad$ Intercept & 0.84 & 0.20 & 4.24 & 5.06 & 0.81 \\
$\quad$ Game losses & -0.014 & 0.004 & -3.38 & $0.00^{*}$ & 0.00 \\
\hline * $p<0.05$. & & & & &
\end{tabular}

Table 4. Effect of stake and reward responsiveness on choice

\begin{tabular}{lrrrll}
\hline & \multicolumn{1}{c}{ S } & \multicolumn{1}{c}{$z$} & $p>z$ & SD $_{\text {RE }}$ \\
\hline BASR $\times$ stake & & & & & \\
$\quad$ Intercept & 1.12 & 0.16 & 6.89 & 0 & 0.95 \\
$\quad$ Stake (100 kr units) & -0.53 & 0.25 & -2.09 & $0.04^{*}$ & 1.45 \\
$\quad$ BAS- $R$ & 0.07 & 0.11 & 0.73 & 0.47 & \\
BASR $\times$ stake & 0.48 & 0.17 & 2.85 & $0.004^{*}$ & \\
\hline${ }^{*}<0.05$. & & & & &
\end{tabular}

\section{The effect of accumulated loss}

We observed a significant interaction between drug group and the magnitude of accumulated loss throughout the game. Accumulated loss reduced gambling in the placebo group but had no effect in the MPH group. See Table 3.

\section{BIS/BAS}

We observed a significant interaction effect between trait reward responsiveness (BAS-R) and stake magnitude on the choice to gamble. Like MPH treatment, higher reward responsiveness was associated with reduced influence of stake magnitude on choice (Table 4). No other BIS/BAS measure had a significant effect; however, drive (BAS-D) produced a trend interaction effect $(p>$ $0.08)$, reflecting its correlation with reward responsiveness $(r=$ $0.5, p<0.002$ ). Adding a three-way drug $\times$ BAS-R $\times$ stake 
interaction effect to the model did not increase its predictive value and did not produce a significant effect. BAS-R and MPH appeared to have additive effects on stake influence at this dose. No BIS/BAS measures predicted the effect of accumulated loss on choice. See Table 4.

\section{Deliberation time}

Drug groups did not significantly differ on deliberation time, but, as a trend, MPH subjects tended to take a bit longer to make their choice $\left(t_{(25)}=1.8, p=0.08\right)$. Deciding to give up took longer than deciding to gamble (Play: $1175 \pm 73$ ms; Quit: $1305 \pm 76$; $\left.F_{(1,35)}=6.2, p<0.02\right)$, but this effect did not interact with drug group $(p>0.6)$. Neither stake nor its interaction with group influenced deliberation time ( $p$ values $>0.25$ ). In a model containing the effects of accumulated loss and drug group effects on deliberation time, however, we did observe a significant main effect of accumulated loss on deliberation time $\left(\beta=-6, t_{(8)}=\right.$ $-3.8, p<0.001)$ and a trend interaction with drug group $(\beta=$ $\left.-3, t_{(8)}=-1.74, p>0.07\right)$. See Table 1.

\section{Discussion}

Both groups gambled significantly more than chance, replicating previous task performances (Campbell-Meiklejohn et al., 2008, 2011). High stakes increased the likelihood of giving up in the placebo group but failed to inhibit persistent gambling in the MPH group. Similarly, only the placebo group gambled less as assets gradually diminished. These findings could not be explained by any other measure.

In economics, investing more following a lost investment despite it being apparently unwise to do so is known as an "escalation of commitment" (Staw, 1981, 1996). Descriptive theories of choice under uncertainty attribute this behavior to the fact that a tentative loss falls on the convex part of a psychophysical function relating monetary value to its subjective value or utility, such that the gain of utility associated with recovery is proportionately greater than the reduction in utility associated with sustaining another loss (Kahneman and Tversky, 2000). The results of this study suggest that catecholamine systems mediate the effect of stake magnitude on this phenomenon, complementing previously established influences of catecholamine activity on other decisions (Cools et al., 2006; Zeeb et al., 2009).

While the failure to inhibit risky choice with high stakes following MPH treatment makes a novel contribution to our understanding of catecholamine mediation of risky behavior, it also leads to the question of how this effect occurs. We present a few possibilities. First, one can frame the decision of this task with a simple model by which choices of a double-or-nothing gamble reflect its expected value, calculated as follows: [probability of recovery $X$ value of recovered] - [probability of further loss $\times$ value of lost stake]. With an estimated probability of recovery that is $<0.5$, the expected value of the gamble will be lower than accepting the current state of affairs. Increasing the stake would enhance this difference and, therefore, the likelihood of giving up. However, impairment on either estimation or application of low reward probability (responding as if probability was closer to 0.5 ), or heightened estimates of recovery value, could theoretically increase the expected value of the gamble and counter the inhibiting effect of high stakes.

So, MPH may have countered the effect of high stakes by impaired adjustment to evidently low reward probability. Supporting this proposal, previous studies of rats have shown that enhanced catecholamine activity can impair behavioral adjustments to changing outcome probabilities (St Onge and Floresco, 2009; St Onge et al., 2010). Similarly, dopaminergic medication in Parkinson's patients can impair behavioral adjustments to negative outcomes (Cools et al., 2001, 2006; Frank et al., 2004). The behavior of rats treated with amphetamine suggests a greater expectancy of reward following near-misses, despite a clear signal that no reward will occur (Winstanley et al., 2011). In humans, amphetamine can change neural and affective responses to cues of upcoming loss to be more like those of upcoming gains (Knutson et al., 2004). In the present study, the MPH group failed to gradually reduce gambling as more losses were encountered. Although this effect is clearly confounded by time spent playing the task, it may have resulted from a failure to learn low probability or adjust behavior accordingly. Such an effect could counter the effect of high stakes. Yet, both treatment groups also maintained a high gambling rate throughout the game. Therefore, it was the case either that neither group accurately learned the low probability of reward from individual decisions or that this was not the sole determinant of decisions to gamble and give up.

MPH could have also increased the estimated value of recovery. Persistent gambling after loss is theorized to be influenced by affective responses to potential outcomes (Lesieur, 1984; Juliusson, 2006; Campbell-Meiklejohn et al., 2008), and positive affective responses (e.g., desire, interest, or hunger) to reward cues are known effects of oral doses of MPH (Volkow et al., 2002, 2004). Presumably, a greater affective response to a reward indicates greater subjective value. Support for such an affective mechanism comes from our finding that trait reward responsiveness produces a similar effect on stake-based inhibition to that of MPH. While the effects of trait reward responsiveness and MPH did not interact at this dose (e.g., a ceiling of reward responsiveness may not have been reached), the common additive effect leaves the possibility that they share a common mechanism open for further research. A state measure of reward responsiveness to loss recovery before and after treatment would be helpful in this regard. If confirmed, the fact that the influence of stake magnitude, but not the influence of accumulated game loss, is associated with reward responsiveness would suggest that MPH modulates the two by separate mechanisms.

MPH may have also affected decisions through effects on other cognitions. For example, it may have engendered less consideration of declining future opportunities to recover when stakes were high and resources were limited (a maximum possible loss). One might also suggest that MPH caused a more general effect of increased stereotyped or perseverative behavior, making the subject generally immune to other influences (Fog, 1969; Scheel-Krüger, 1972). Randomization of choice-button associations rules out a simple motor stereotypy account of the findings, while a similarity between groups with respect to repeating the previous choice can rule out a general effect of MPH on choice stickiness. MPH may have caused stricter adherence to more complex choice patterns, although such patterns would likely differ from subject to subject and are difficult to pinpoint. In the future, it will be worth exploring how the effect of MPH to prevent inhibition by high stakes generalizes to effects on the influence of other cues. To begin, one could investigate the effect of $\mathrm{MPH}$ on the influence of cues that normally increase gambling, which is hinted by a trend reduction of gambling at lower stakes, relative to placebo. Since no clear indications to increase gambling were present in this task, the current results speak only to diminished inhibition.

The effect of MPH on stake was very similar to the effect of pramipexole, a direct $\mathrm{D}_{2} / \mathrm{D}_{3}$ receptor agonist (CampbellMeiklejohn et al., 2011). Like MPH, pramipexole increases stakes associated with gambling, without affecting overall gambling rates. 
Also in the earlier study, no effect on choice was found by a $\beta$-adrenergic receptor blocker, propranolol, making enhanced dopamine activity a good candidate for a pharmacological mechanism of MPH effects reported here. The roles of $\alpha$-adrenergic receptors (Gamo et al., 2010), however, still require formal testing.

Our findings suggest that use of stimulants for "cognitive enhancement" by healthy adults may increase their tendency to persistently take risks despite cues to do otherwise. The results also strengthen parallels that have been speculatively drawn between the etiology and effects of problem gambling, abuse of psychotropic stimulants, and other pharmacological addictions (Zack and Poulos, 2009; Leeman and Potenza, 2012). For example, amphetamine can prime gambling-related cognition and increase the desire to gamble in pathological gamblers (Zack and Poulos, 2004). One explanation is that dopamine mediates the intrinsic enjoyment of gambling. However, our findings suggest that it could also derive from reduced influence by inhibitory cues, perhaps due to increased responding to potential gains (Voon et al., 2010). The results also emphasize the importance of observing the impact of inhibitory cues when examining the relationship between impulse control disorders and dopaminergic medication.

Future studies may also wish to consider the following. First, in this study, subjects were informed that the best possible outcome would not occur by choosing an exclusive choice policy of playing or quitting. Hypothetically, this instruction may have nudged subjects away from a preferred normative strategy to always quit in light of a low gamble success rate (note, however, consistently high gambling rates provided no indication that subjects would have preferred to exclusively quit). Researchers may wish to consider excluding this instruction. Second, we used a competitive game structure for payoffs. This may have caused subjects to accept more risks than they would have done otherwise, for the slim possibility of gaining an edge on other players. It would be desirable to replicate this effect without the competitive game structure. Likewise, it would be desirable to test the generalizability of the findings to real monetary outcomes, a variety of cost types (e.g., effort), real gambling environments, and situations with full knowledge of declining assets. Finally, despite female gender being a predictor of impulse control disorder onset following dopamine agonist treatment (Voon et al., 2011) and approximately one-third of diagnosed pathological gamblers being female (Volberg and Steadman, 1988; Bland et al., 1993), further work is needed establish the effects in males.

\section{Conclusion}

Overall, the findings suggest that MPH reduces inhibitory influences on risky behavior after experiencing a loss, resulting in more frequent gambling at higher stakes. This is new evidence for a catecholamine-mediated mechanism determining persistent risky choice.

\section{References}

Bates D, Maechler M (2009) Linear mixed-effects models using S4 classes. In: R package version 0.999375-45. Vienna, Austria: R Foundation.

Berridge CW, Devilbiss DM, Andrzejewski ME, Arnsten AF, Kelley AE, Schmeichel B, Hamilton C, Spencer RC (2006) Methylphenidate preferentially increases catecholamine neurotransmission within the prefrontal cortex at low doses that enhance cognitive function. Biol Psychiatry 60:1111-1120. CrossRef Medline

Binswanger HP (1981) Attitudes toward risk: theoretical implications of an experiment in rural India. Econ J 91:867-890. CrossRef

Bland RC, Newman SC, Orn H, Stebelsky G (1993) Epidemiology of pathological gambling in Edmonton. Can J Psychiatry 38:108-112. Medline
Campbell-Meiklejohn DK, Woolrich MW, Passingham RE, Rogers RD (2008) Knowing when to stop: the brain mechanisms of chasing losses. Biol Psychiatry 63:293-300. CrossRef Medline

Campbell-Meiklejohn D, Wakeley J, Herbert V, Cook J, Scollo P, Ray MK, Selvaraj S, Passingham RE, Cowen P, Rogers RD (2011) Serotonin and dopamine play complementary roles in gambling to recover losses. Neuropsychopharmacology 36:402-410. CrossRef Medline

Carver CS, White TL (1994) Behavioral-inhibition, behavioral activation, and affective responses to impending reward and punishment-the BIS BAS scales. J Pers Soc Psychol 67:319-333. CrossRef

Clatworthy PL, Lewis SJ, Brichard L, Hong YT, Izquierdo D, Clark L, Cools R, Aigbirhio FI, Baron JC, Fryer TD, Robbins TW (2009) Dopamine release in dissociable striatal subregions predicts the different effects of oral methylphenidate on reversal learning and spatial working memory. J Neurosci 29:4690-4696. CrossRef Medline

Cools R, Barker RA, Sahakian BJ, Robbins TW (2001) Enhanced or impaired cognitive function in Parkinson's disease as a function of dopaminergic medication and task demands. Cereb Cortex 11:1136-1143. CrossRef Medline

Cools R, Altamirano L, D’Esposito M (2006) Reversal learning in Parkinson's disease depends on medication status and outcome valence. Neuropsychologia 44:1663-1673. CrossRef Medline

Cubitt R, Starmer C, Sugden R (1998) On the validity of the random lottery incentive system. Exp Econ 1:115-131. CrossRef

DeVito EE, Blackwell AD, Kent L, Ersche KD, Clark L, Salmond CH, Dezsery AM, Sahakian BJ (2008) The effects of methylphenidate on decision making in attention-deficit/hyperactivity disorder. Biol Psychiatry 64: 636-639. CrossRef Medline

Field A (2009) Discovering statistics using SPSS. London: SAGE.

Fog R (1969) Stereotyped and non-stereotyped behaviour in rats induced by various stimulant drugs. Psychopharmacologia 14:299-304. CrossRef Medline

Frank MJ, Seeberger LC, O'reilly RC (2004) By carrot or by stick: cognitive reinforcement learning in parkinsonism. Science 306:1940-1943. CrossRef Medline

Gamo NJ, Wang M, Arnsten AF (2010) Methylphenidate and atomoxetine enhance prefrontal function through $\alpha 2$-adrenergic and dopamine D1 receptors. J Am Acad Child Adolesc Psychiatry 49:1011-1023. CrossRef Medline

Holt C, Laury S (2002) Risk aversion and incentive effects. Am Econ Rev 92:1644-1655. CrossRef

Holt C, Laury S (2005) Risk aversion and incentive effects: new data without order effects. Am Econ Rev 95:902-904. CrossRef

Juliusson A (2006) Optimism as modifier of escalation of commitment. Scand J Psychol 47:345-348. CrossRef Medline

Kahneman D, Tversky A (2000) Choices, values, and frames. Cambridge, UK: Cambridge UP.

Knutson B, Bjork JM, Fong GW, Hommer D, Mattay VS, Weinberger DR (2004) Amphetamine modulates human incentive processing. Neuron 43:261-269. CrossRef Medline

Leeman RF, Potenza MN (2012) Similarities and differences between pathological gambling and substance use disorders: a focus on impulsivity and compulsivity. Psychopharmacology (Berl) 219:469-490. CrossRef Medline

Lesieur H (1984) The chase: career of the compulsive gambler. Rochester, Vermont: Schenkman Books.

Lesieur HR, Blume SB (1987) The South Oaks Gambling Screen (SOGS): a new instrument for the identification of pathological gamblers. Am J Psychiatry 144:1184-1188. Medline

O'Connor J, Dickerson M (2003) Definition and measurement of chasing in off-course betting and gaming machine play. J Gambl Stud 19:359-386. CrossRef Medline

Rahman S, Robbins TW, Hodges JR, Mehta MA, Nestor PJ, Clark L, Sahakian BJ (2006) Methylphenidate ("Ritalin") can ameliorate abnormal risktaking behavior in the frontal variant of frontotemporal dementia. Neuropsychopharmacology 31:651-658. CrossRef Medline

Raylu N, Oei TP (2004) The Gambling Related Cognitions Scale (GRCS): development, confirmatory factor validation and psychometric properties. Addiction 99:757-769. CrossRef Medline

Robbins TW, Arnsten AF (2009) The neuropsychopharmacology of frontoexecutive function: monoaminergic modulation. Annu Rev Neurosci 32: 267-287. CrossRef Medline 
Rogers RD, Wielenberg B, Wojtecki L, Elben S, Campbell-Meiklejohn D, Schnitzler A (2011) Deep brain stimulation of the subthalamic nucleus transiently enhances loss-chasing behaviour in patients with Parkinson's Disease. Exp Neurol 231:181-189. CrossRef Medline

Scheel-Krüger J (1972) Behavioural and biochemical comparison of amphetamine derivatives, cocaine, benztropine and tricyclic anti-depressant drugs. Eur J Pharmacol 18:63-73. CrossRef Medline

Shiels K, Hawk LW Jr, Reynolds B, Mazzullo RJ, Rhodes JD, Pelham WE Jr, Waxmonsky JG, Gangloff BP (2009) Effects of methylphenidate on discounting of delayed rewards in attention deficit/hyperactivity disorder. Exp Clin Psychopharmacol 17:291-301. CrossRef Medline

Smith ME, Farah MJ (2011) Are prescription stimulants "smart pills"? The epidemiology and cognitive neuroscience of prescription stimulant use by normal healthy individuals. Psychol Bull 137:717-741. CrossRef Medline

Spielberger CD (1970) STAI manual. Washington, DC: Consulting Psychologists Press.

Staw BM (1981) The escalation of commitment: a review and analysis. Acad Manage Rev 6:577-587. CrossRef

Staw BM (1996) The escalation of commitment: an update and appraisal. In: Organizational decision making (Shapira Z, ed), pp 191-215. Cambridge: Cambridge UP.

St Onge JR, Floresco SB (2009) Dopaminergic modulation of risk-based decision making. Neuropsychopharmacology 34:681-697. CrossRef Medline

St Onge JR, Chiu YC, Floresco SB (2010) Differential effects of dopaminergic manipulations on risky choice. Psychopharmacology (Berl) 211:209221. CrossRef Medline

Volberg RA, Steadman HJ (1988) Refining prevalence estimates of pathological gambling. Am J Psychiatry 145:502-505. Medline

Volkow ND, Wang G, Fowler JS, Logan J, Gerasimov M, Maynard L, Ding Y, Gatley SJ, Gifford A, Franceschi D (2001) Therapeutic doses of oral methylphenidate significantly increase extracellular dopamine in the human brain. J Neurosci 21:RC121. Medline

Volkow ND, Wang GJ, Fowler JS, Logan J, Jayne M, Franceschi D, Wong C, Gatley SJ, Gifford AN, Ding YS, Pappas N (2002) Nonhedonic food motivation in humans involves dopamine in the dorsal striatum and methylphenidate amplifies this effect. Synapse 44:175-180. CrossRef Medline Volkow ND, Wang GJ, Fowler JS, Telang F, Maynard L, Logan J, Gatley SJ,
Pappas N, Wong C, Vaska P, Zhu W, Swanson JM (2004) Evidence that methylphenidate enhances the saliency of a mathematical task by increasing dopamine in the human brain. Am J Psychiatry 161:1173-1180. CrossRef Medline

Voon V, Pessiglione M, Brezing C, Gallea C, Fernandez HH, Dolan RJ, Hallett M (2010) Mechanisms underlying dopamine-mediated reward bias in compulsive behaviors. Neuron 65:135-142. CrossRef Medline

Voon V, Schoerling A, Wenzel S, Ekanayake V, Reiff J, Trenkwalder C, SixelDöring F (2011) Frequency of impulse control behaviours associated with dopaminergic therapy in restless legs syndrome. BMC Neurol 11: 117. CrossRef Medline

Watson D, Clark LA, Tellegen A (1988) Development and validation of brief measures of positive and negative affect: the PANAS scales. J Pers Soc Psychol 54:1063-1070. CrossRef Medline

Wechsler D (2005) Wechsler Adult Intelligence Scale, Danish version III edition. Boston, MA: Pearson Assessment.

Weintraub D, Koester J, Potenza MN, Siderowf AD, Stacy M, Voon V, Whetteckey J, Wunderlich GR, Lang AE (2010) Impulse control disorders in Parkinson disease: a cross-sectional study of 3090 patients. Arch Neurol 67:589-595. CrossRef Medline

Wilens TE (2008) Effects of methylphenidate on the catecholaminergic system in attention-deficit/hyperactivity disorder. J Clin Psychopharmacol 28:S46-S53. CrossRef Medline

Winstanley CA, Cocker PJ, Rogers RD (2011) Dopamine modulates reward expectancy during performance of a slot machine task in rats: evidence for a "near-miss" effect. Neuropsychopharmacology 36:913-925. CrossRef Medline

Zack M, Poulos CX (2004) Amphetamine primes motivation to gamble and gambling-related semantic networks in problem gamblers. Neuropsychopharmacology 29:195-207. CrossRef Medline

Zack M, Poulos CX (2009) Parallel roles for dopamine in pathological gambling and psychostimulant addiction. Curr Drug Abuse Rev 2:11-25. Medline

Zeeb FD, Robbins TW, Winstanley CA (2009) Serotonergic and dopaminergic modulation of gambling behavior as assessed using a novel rat gambling task. Neuropsychopharmacology 34:2329-2343. CrossRef Medline 